\title{
DEM simulation research of selected sowing unit elements used in a mechanical seeding drill
}

\author{
Jacek Marcinkiewicz ${ }^{1, *}$, Jarosław Selech ${ }^{1}$, Żaneta Staszak $^{1}$, Lukasz Gierz ${ }^{1}$, Dariusz \\ Ulbrich $^{1}$, and Dawid Romek ${ }^{1}$ \\ ${ }^{1}$ Poznan University of Technology, Institute of Machines and Motor Vehicles, Marii Sklodowskiej 5 \\ sq. 60-965 Poznan, Poland
}

\begin{abstract}
The paper presents the results of research aimed at the verification of the existing design solutions of four example sowing units for agricultural seed drills with the most frequently used types of sowing wheels. The research was conducted with the use of modern computer simulation systems based on the discrete element method (DEM) with the evaluation of the efficiency of selected design solutions in terms of achieved performance and metering uniformity. The paper includes a description of virtual research models and the employed mathematical models used for mirroring contact between seeds. Moreover, for the purpose of verification of the obtained results, bench tests were conducted using actual models of selected design solutions.
\end{abstract}

Keywords: DEM, sowing, granular materials, agricultural technologies

\section{Introduction}

Technological development within the agricultural machinery sector is oriented at obtaining higher yields, while maintaining the highest quality, decreasing production costs, and limiting contamination of the environment. To this end, existing agricultural machinery designs are now modified, with brand new solutions - created using state-of-the-art technologies developed and introduced. One of the areas of intensified research are components of sowing machines which are directly responsible for proper and even application of seeds below the surface of the soil, which makes it possible to achieve higher performance with lower amount of the seeding material. The type of seed drills used most frequently by farmers are generalpurpose universal in-line seed drills. This type of design is characterised by a relatively simple operating principle consisting in raking seeds from the seed hopper by the sowing units and moving them downstream through the seed tube into the furrow made by the furrow opener.

One of the crucial operating parameters of the agricultural seed drill is an even seed flow. This factor determines the machine's efficiency verified by the yield of the sown field. The main component of the seed drill that impacts the uniformity of seed metering is the sowing

\footnotetext{
${ }^{*}$ Corresponding author: jacek.marcinkiewicz@put.poznan.pl.

Reviewers: Tomasz Domański, Milan Žmindák
} 
unit whose key parameters are its design and technological features [1, 2]. Hence continuous efforts are made to improve the sowing unit's geometry enabling even more accurate execution of the task. To date, this task has been performed with the use of empirical research methods and experimental stands requiring physical models of newly developed solutions to be constructed (Fig. 1). Due to the presence of rather complex geometries in the design of sowing rollers, their multi-variant prototyping can be troublesome, time-consuming, and costly. Therefore, the use of virtual tests considerably simplifies the task. Continuous progress of research in the area of simulation with the use of computer environments makes it possible to develop increasingly perfected research tools that significantly limit the need to use expensive experimental research. Computer simulations can be used for studying many processes present in agricultural machines, including sowing machinery where we deal with the phenomenon of seed movement, in-depth understanding of which constitutes a vital aspect in the process of searching for new design solutions or improving the existing ones. Unfortunately, this involves a number of issues caused by the non-uniform, non-continuous, and anisotropic nature of granular materials.

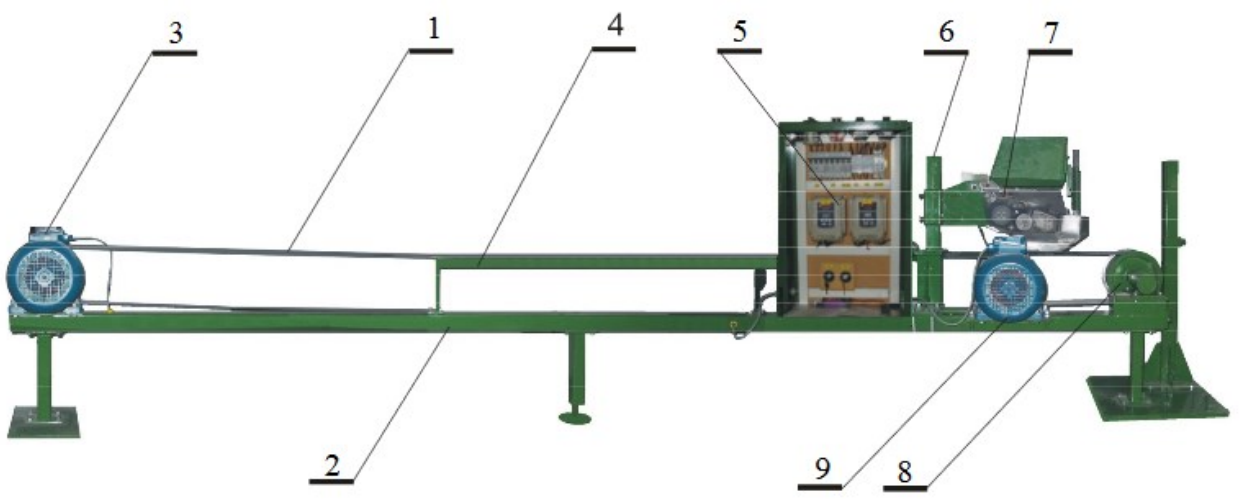

Fig. 1. Sowing unit test stand (University of Life Sciences in Lublin) [3]: 1 - adhesive tape, 2 - test stand frame, 3 - electric motor of the adhesive tape drive, 4 - adhesive tape guide, 5 - pack of frequency transducers, 6 - sowing sectionsupport, 7 - sowing section, 8 - adhesive tape tension roll, 9 - electric motor of the sowing section drive

Today, the discrete element method (DEM) [4] is gaining favour in the modelling of granular material behaviour and it was used in this study to test four different sowing units. The obtained results were further verified for one of the solutions on an actual special experimental stand. The aim of this paper was to confirm that the assumptions adopted for the purpose of DEM simulation were correct and compare the selected design solutions in terms of achieved performance and metering uniformity.

\section{Research object characteristics}

The research described in the article concerns the sowing unit of a universal mechanical inline seed drill from the perspective of geometrical solutions for sowing rollers (Fig. 2). Systems of this type primarily use peg sowing units $[5,6]$ whose operation consists in raking seed from the seed hopper, which is then transported by the rotating sowing roller to the seed tube. The raking is caused by face pressure exerted by the peg surface and the friction force between the seeds and the side surface of the pegs, as well as the friction force between the seeds themselves. To ensure that the space between the pegs is filled evenly, the flow of seed from the main hopper is adjusted with a special sliding shutter and the operating area of the roller is limited with partitions on the side. Additionally, there is a spring-loaded bottom in 
the lower section of the roller. This solution enables the bottom to deflect when a foreign object (e.g. a rock) makes its way to the sowing roller, which safeguards the entire structure against damage.

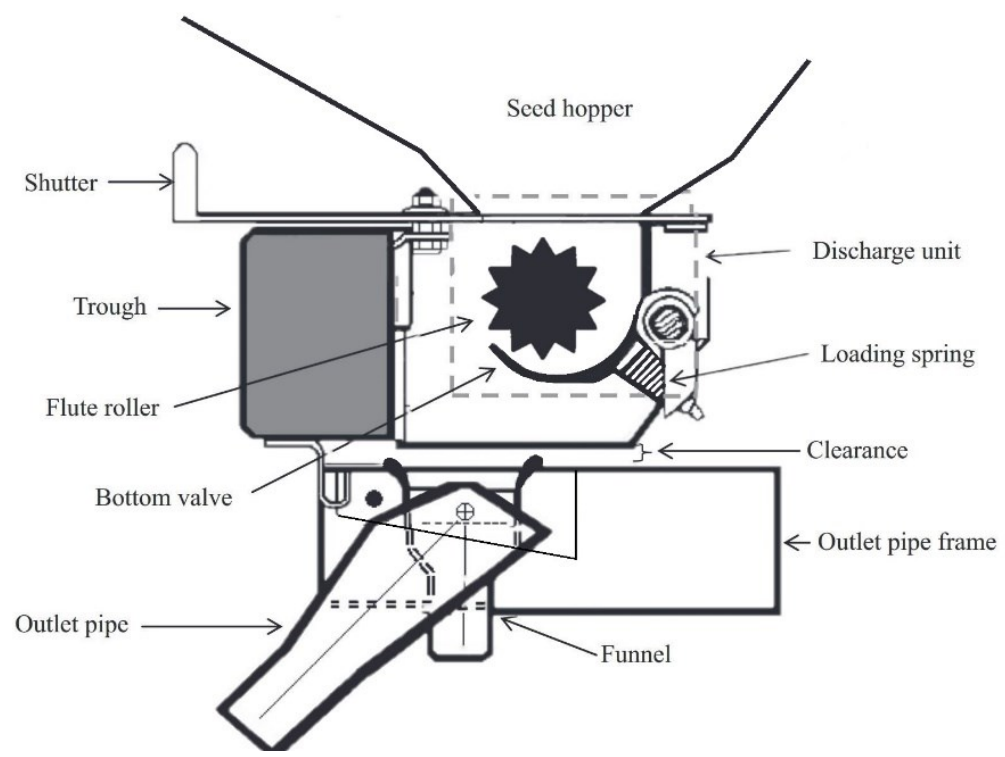

Fig. 2. Simplified sketch of the seed discharge unit [7]

The design of the peg sowing unit is a proven and readily employed solution, yet it has its downsides. Because the sowing roller has to work along its entire length, this type of solution provides little adjustment of the amount of seeds sown. Performance can only be increased or decreased by changing the rotational speed of the sowing roller. Moreover, a number of studies have shown the existence of the seed flow pulsing phenomenon, meaning a non-continuous flow of seeds, which in turn directly translates into a decreased evenness of sowing $[8,9]$. Over time, attempts to solve this issue resulted in many versions of sowing rollers differing both in terms of the number and the shape of protruding parts.

For the purpose of this paper, four different geometrical solutions of sowing peg rollers constituting segments for sowing medium grains were chosen for discussion. The selected geometries are representative of the shapes that are used most frequently. All of the discussed rollers were fitted along their circumference with 24 pegs in two rows offset by half pitch from one another. The small differences between the models mainly concern the shape and dimensions of the raking pegs and the dimensions of individual segments. The first one of the analysed geometries is characterised by active surfaces of the pegs in the form of an involute profile (Fig. 3a). The next two rollers constitute some of the simplest solutions, wherein the peg surfaces are rectangular (Fig. 3b) and trapezoidal elements (Fig. 3c), respectively. The last one of the discussed designs shows more departures from the basic idea of the peg sowing unit. The sowing roller shown in Fig. 3d features much wider raking pegs (flutes) spanning along the entire width of the row. Furthermore, the peg profile of the fourth discussed solution can be considered exceptional, because it has an asymmetrical triangular geometry. 
a)

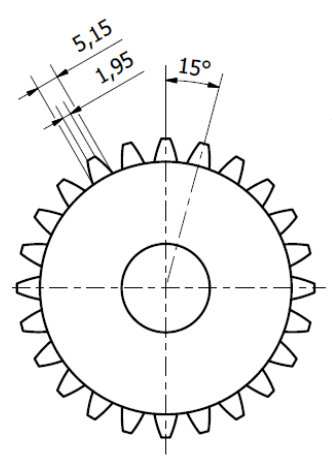

c)

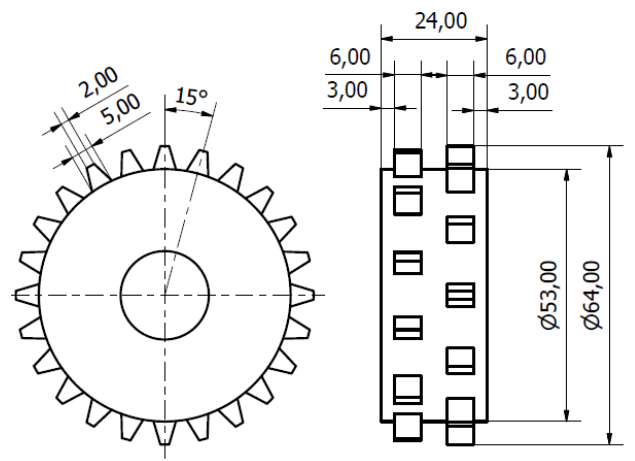

b)
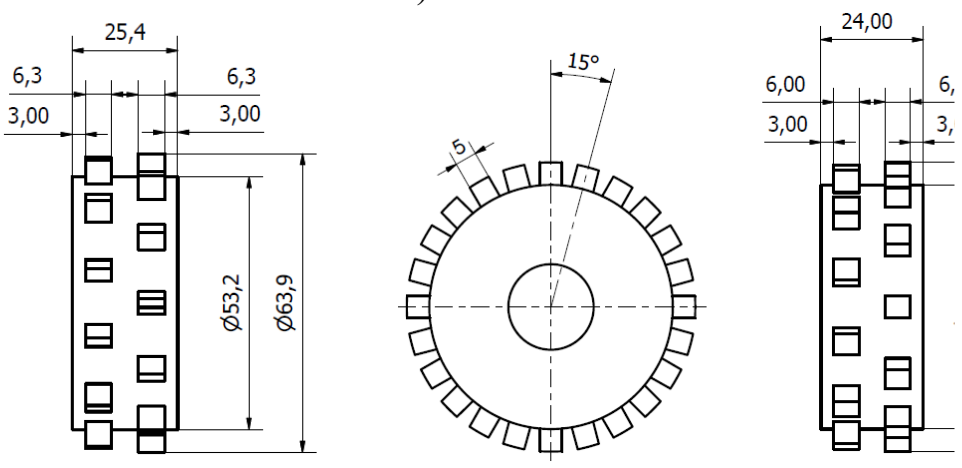

d)

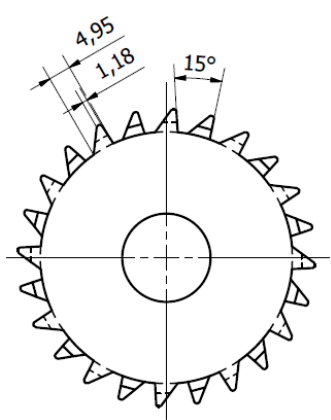

Fig. 3. Basic dimensions of the studied sowing rollers for four different sowing pegs: a) involute, b) rectangular, c) trapezoidal, and d) triangular

\section{DEM studies}

Simulation studies were conducted using the discrete element method (DEM), making it possible to reflect the interactions occurring in the fragmented materials, that is forces occurring during particle contact, and observe the effect of these interactions on the macroscopic properties of the collected material. This method uses simplifications such as representations of e.g. granular bodies as spherical particles for modelling fragmented material. In DEM, the interactions between the studied particles during their collisions caused by external forces are described using mathematical contact models developed especially for this purpose. These models are built based on numerous laboratory experiments, which allows them to reflect the actual behaviour of the material and its parameters. In terms of reflecting spring contacts, the Hertz [10] and Mindlin-Deresiewicz [11] models are the most frequently used tools for determining tangential and normal components of force. However, there are certain material groups that are characterised by certain forms of energy dissipation, which are represented, among others, by the elastic-plastic and adhesive-elastic [12, 13, 14, 15] models. Basic assumptions in the construction of the most frequently used models include above all the isotropy and elasticity of the represented particles. Moreover, for the purpose of simplification, it is assumed that the tangential area of particles is small in comparison to the main dimensions and that contact surfaces are completely smooth [16]. To date, many 
articles describing the physical properties of granular materials and physical models of interactions occurring between them have been published [17-24].

\subsection{Simulation model}

The experiment described in this article consisted in simulating the operation of four different peg units while sowing $0.20 \mathrm{~kg}$ of wheat seeds, which corresponded to 8,000 particles. For the purpose of the performed simulations, a simplified model of the sowing unit was developed consisting of a single metering section as shown in Fig. 4. The design of the model features two fundamental geometrical elements: a fixed body, identical for all the considered cases, and a sowing wheel seated in a manner enabling rotation. The inner partitions of the housing were shaped based on the inclination used in seed hoppers, which enabled continuous feeding of the sowing material to the sowing roller. For the purpose of the simulation, it was assumed that the housing is made of ordinary structural steel and the sowing wheel is made of polyethylene.

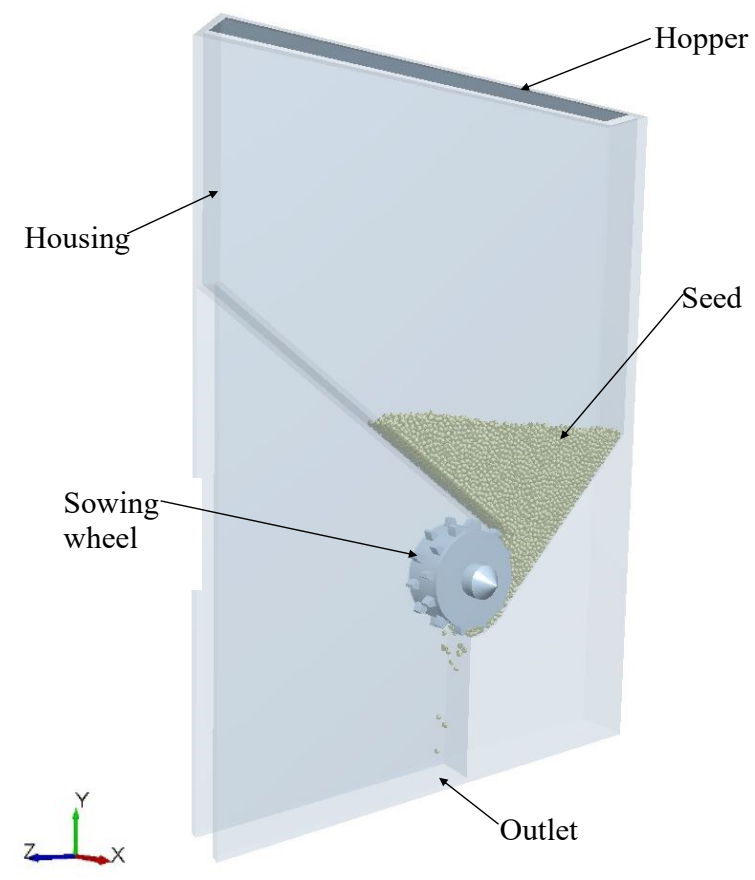

Fig. 4. DEM model

Plant material in the form of winter wheat of the Begra variety, whose physical parameters are provided in Table 1, was used in the studies. The virtual representation of the seed was designed as a geometrical three-dimensional structure made up of a complex of five inseparably connected spheres (Fig. 5), whose centres are located on a common axis of symmetry. To recreate the shape of the particle as accurately as possible, the spheres were positioned so that they overlapped and had various dimensions. Individual diameters were selected in accordance with Table 2 . The shape of the seed was approximated by inscribing spheres so that the surface of each of them was tangent to the surface of the seed particle at the point of contact. This method is widely used in the DEM and is well-known as the multisphere method. It has successfully been used by many researchers to represent the geometrical characteristics of many types of seeds and grains, such as pea, bean, [25], corn[26], rice [27], soy [18], and wheat [29]. 
Table 1. Input parameters for DEM modelling [30]

\begin{tabular}{|c|c|}
\hline Property name & Begra wheat \\
\hline Poisson's ratio $v[-]$ & 0.2 \\
\hline Shear modulus $G[\mathrm{MPa}]$ & 9 \\
\hline Particle friction coefficient $\mu[-]$ & 0.25 \\
\hline Damping ratio $\delta_{N}[\mathrm{~kg} / \mathrm{s}]$ & 0.7 \\
\hline Damping ratio $\delta_{S}[\mathrm{~kg} / \mathrm{s}]$ & 0.5 \\
\hline Material density $\rho_{S}\left[\mathrm{~kg} / \mathrm{m}^{3}\right]$ & 1,550 \\
\hline Numerical strength of the particle set $N[-]$ & 8,000 \\
\hline
\end{tabular}

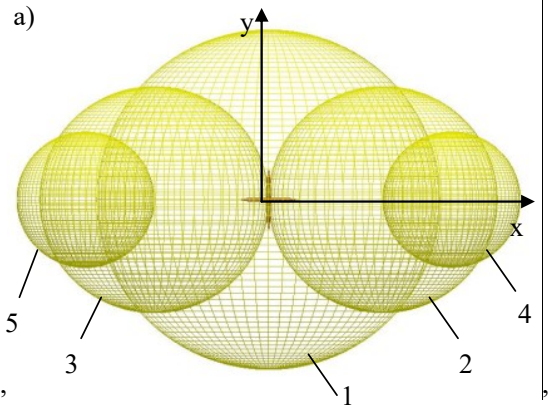

b)

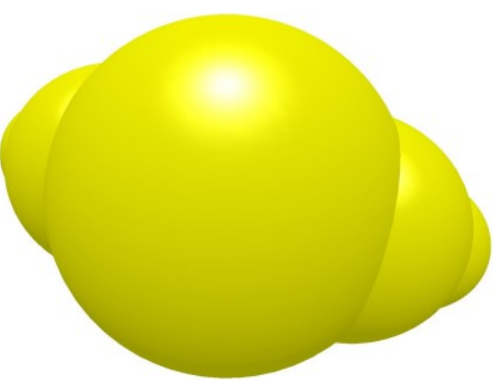

Fig. 5. Seed model view: a) individual components, b) overview

Table 2. Geometrical parameters of seed model components shown in Fig. 5 [31]

\begin{tabular}{|c|c|c|c|}
\hline \multirow{2}{*}{ Item } & \multirow{2}{*}{ Diameter [mm] } & \multicolumn{2}{|c|}{ Position of centre of mass [mm] } \\
\cline { 3 - 4 } & 3.0 & $\mathrm{x}$ & $\mathrm{y}$ \\
\hline 1 & 2.0 & 0.0 & 0.0 \\
\hline 2 & 2.0 & 1.0 & 0.0 \\
\hline 3 & 1.2 & -1.0 & 0.0 \\
\hline 4 & 1.2 & 1.6 & 0.0 \\
\hline 5 & & -1.6 & 0.0 \\
\hline
\end{tabular}

Simulations were performed at 20\% Rayleigh time step. The force-displacement law at contact points for all of the simulations was represented by a Hertz-Mindlin no-slip contact model. In this model, the contact forces applied to colliding particles result from dependence (1) and (2):

$$
\begin{gathered}
F_{N}=\frac{2 G \sqrt{2 r}}{3(1-v)} \Delta n^{3 / 2}-\delta_{N} V_{N}, \\
F_{S}=\frac{2 \sqrt[3]{3 G^{2}(1-v) r}}{2-v} \sqrt[3]{\left|F_{N}\right|} V_{S} \Delta t-\delta_{S} V_{S} \text { when } F_{S} \leq \mu\left|F_{N}\right|,
\end{gathered}
$$

where: $F_{N}, F_{S}$ - contact forces in the normal and tangent direction [N], $v$ - Poisson's ratio [-] $G$ - shear modulus [Pa], $r$ - average radius of both particles $k[\mathrm{~m}], \delta_{N}, \delta_{S}-$ normal and tangent damping ratio $[\mathrm{kg} / \mathrm{s}], V_{N}, V_{S}$ - particle speed in normal and tangent direction $[\mathrm{m} / \mathrm{s}]$, $\mu$ - friction coefficient [-], $\Delta n$ - length of the common area of particles in normal direction $[\mathrm{m}], \Delta t-$ time step $[\mathrm{s}]$. 


\subsection{Simulation tests}

The simulation tests conducted for each of the discussed cases were identical. Each simulation started with the feeding of particles representing wheat seeds into the housing chamber of the test model. The free-flow feeding was done from the top, thereby ensuring natural positioning of the sowing material in the bottom section of the hopper. The freely piled set of particles was created by applying the gravity force and performing a small number of calculation steps until stationary state was achieved. At a further stage of the simulation, the sowing roller was rotated at predetermined speed of $10 \mathrm{rpm}$, identical for all the simulations performed. Next, the material transported by the wheel fell freely and was not collected further. The calculation process was run until the hopper was completely emptied.

\section{Simulation results}

As a result of the conducted simulation tests of four comparable sowing units, information about basic operating parameters was obtained. Each time, an output of 8,000 seeds was simulated, thanks to which the obtained results enabled visualisation of seed movement inside the analysed peg units. The obtained results made it possible to trace the entire path of the seed from the moment it was poured into the hopper, through complex transport around the circumference of the metering wheel, until it left the sowing unit. The test model housing was shaped so as to enable easy observation of the occurrence of the uneven sowing phenomenon. The observation was conducted over the section between the edge of the output (the point of last contact with the rotating sowing wheel) and the bottom section of the housing. This is also the point where the distance between free-falling seeds was measured.

The first design selected for the simulation discussion was the sowing element with an involute peg profile (Fig. 6). The analysis showed that the time required to transport all the seeds from the main hopper was $59.1 \mathrm{~s}$. This means that for the boundary conditions adopted for the study, the discussed sowing unit demonstrated performance of $203.03 \mathrm{~g} / \mathrm{min}^{-1}$. Furthermore, simulations revealed the occurrence of the phenomenon of portioning of the flow of seeds (unevenness). The largest observed distance between seed portions in the measurement section was $22.9 \mathrm{~mm}$.

The next discussed case was the unit fitted with a roller with a rectangular profile of the sowing pegs (Fig. 7). The simplest of the simulated shapes needed $66.1 \mathrm{~s}$ to sow all 8,000 seeds. The performance achieved in the tests was $181.54 \mathrm{~g} / \mathrm{min}^{-1}$. During operation, the phenomenon of portioning of the flow of seeds was clearly visible, which was also manifested in the largest observed gap of $39.02 \mathrm{~mm}$. Moreover, a detailed analysis of the course of simulation showed the occurrence of frequent wedging of seeds in the area between the face of the sowing peg and the surface of the housing. The wide vertex of the rotating sowing wheel caused crushing forces to occur, which in practice could damage the transported material.

The tests carried out using the sowing roller featuring trapezoidal profile pegs (Fig. 8) showed that the time required to sow the assumed number of seeds was $58.1 \mathrm{~s}$. The obtained performance reached the level of $207.54 \mathrm{~g} / \mathrm{min}^{-1}$. The simulation results of the third analysed case showed no significant differences in the performance parameters versus the involute profile variant. The unevenness of sowing also showed similarities to the first tested variant, while the largest gap measured between the seeds was $23.26 \mathrm{~mm}$.

The last considered case was the sowing unit fitted with triangular raking elements (Fig. 9). The test showed results comparable to the involute sowing unit. The time required to sow the predetermined number of seeds was $59.5 \mathrm{~s}$, which translates into the performance of $201.68 \mathrm{~g} / \mathrm{min}^{-1}$. Just like in the previous cases, also this time the fed stream of seeds showed symptoms of the phenomenon of unevenness. The largest gap observed between falling seeds 
was $21.12 \mathrm{~mm}$. Based on analysis results, it was noticeable that this geometry ensured higher repeatability of filling the tooth gaps in comparison to the other discussed designs. Furthermore, the raking of seed from the seed hopper is less invasive and the phenomena that could damage the transported material are less frequent.

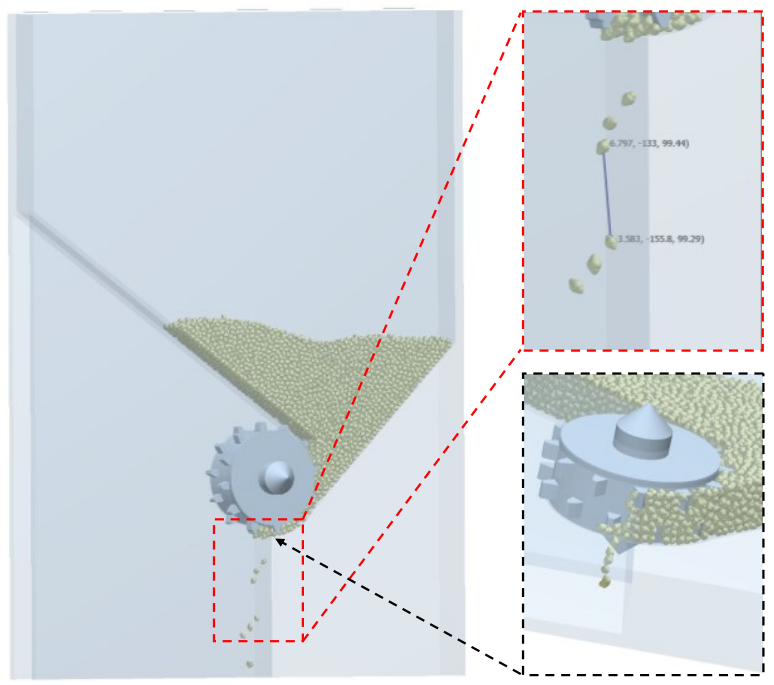

Fig. 6. Simulation result from the first simulation unit

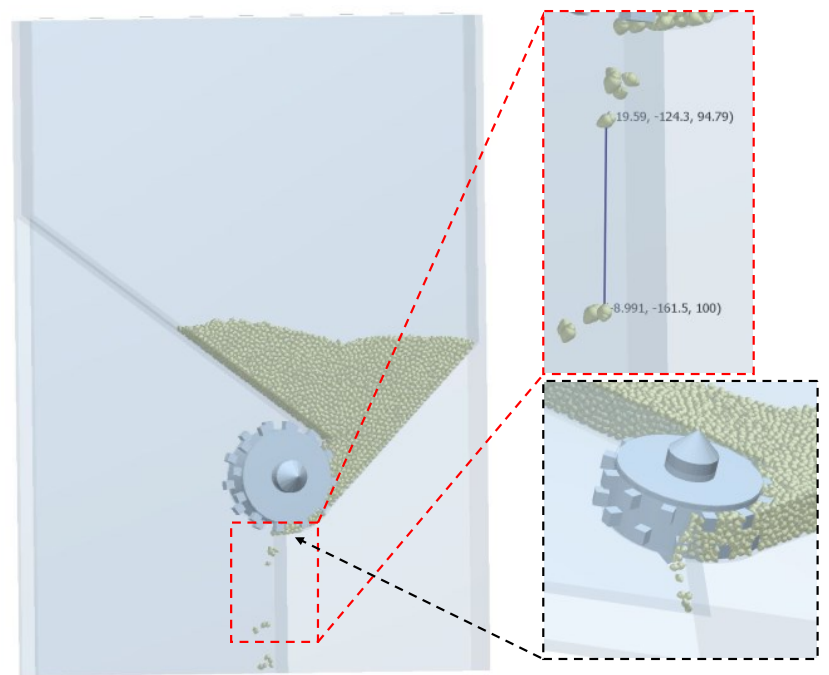

Fig. 7. Simulation result from the second simulation unit 


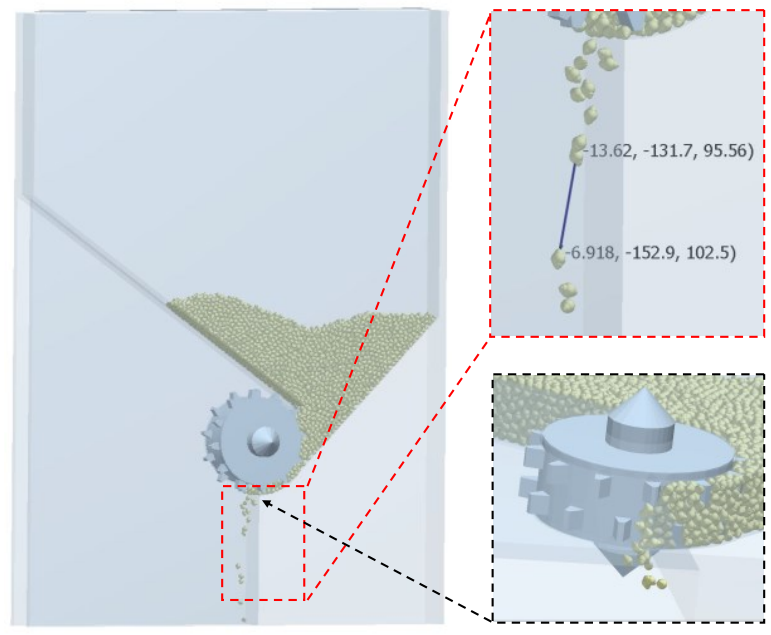

Fig. 8. Simulation result from the third simulation unit

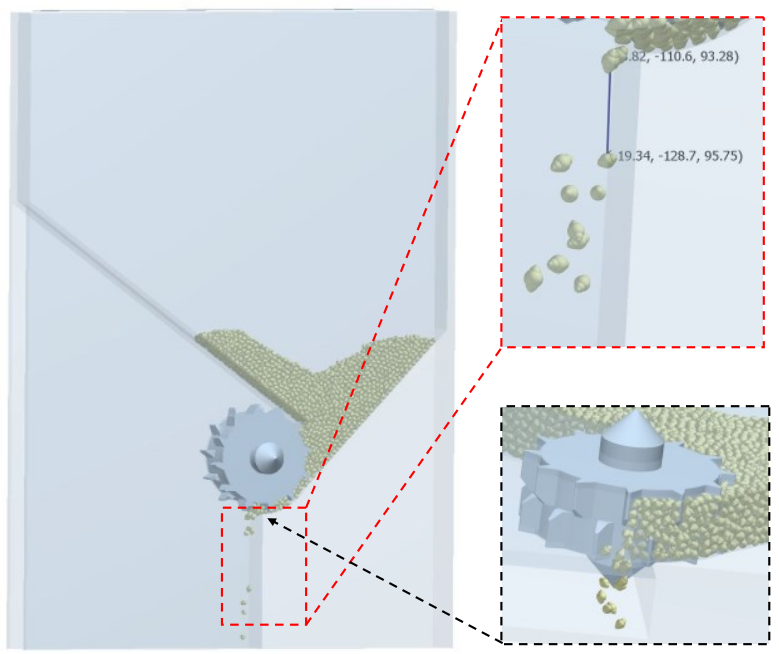

Fig. 9. Simulation result from the fourth simulation unit

\section{Bench tests}

The simulation tests and the constitutive models of force application between the particles employed in the simulation tests constitute only an approximation of the conditions present in the real world. Mathematical models are not able to perfectly represent the effect of all the factors and their variability encountered in the real world. Therefore, for the purpose of verification of the conducted research, experimental research was carried out for one of the selected geometrical solutions of the peg sowing units. A specially prepared test bench was used (Fig. 10), the design of which featured a housing with a single sowing wheel (sowing unit with an involute peg profile) and an electric drive unit.

The bench tests were performed in accordance with the assumptions adopted for the purpose of the DEM tests. All the geometrical dimensions of key structural elements were in 
line with the simulation model. The sowing roller installed on the test bench rotated at a speed of 10 RPM. During each of the trials, $0.20 \mathrm{~kg}$ of wheat of the Begra variety was sown.

Sowing time measurements taken in ten trials yielded an average result of $61.4 \mathrm{~s}$. This was very similar to the result obtained in the DEM simulation tests. The difference was only $2.3 \mathrm{~s}$.

In order to examine the phenomenon of seed stream feed evenness to the full extent, it would be necessary to build a test bench using much more accurate laboratory instruments, e.g. in the form of cameras for taking quick pictures or a system using special sensors along with software and measuring amplifiers providing the option to record moving seeds. In this case, the focus was on determining whether in the tested design of the sowing mechanism, the phenomenon of unevenness of sowing occurred and what its intensity was, and for this purpose, the test stand used was fully sufficient.

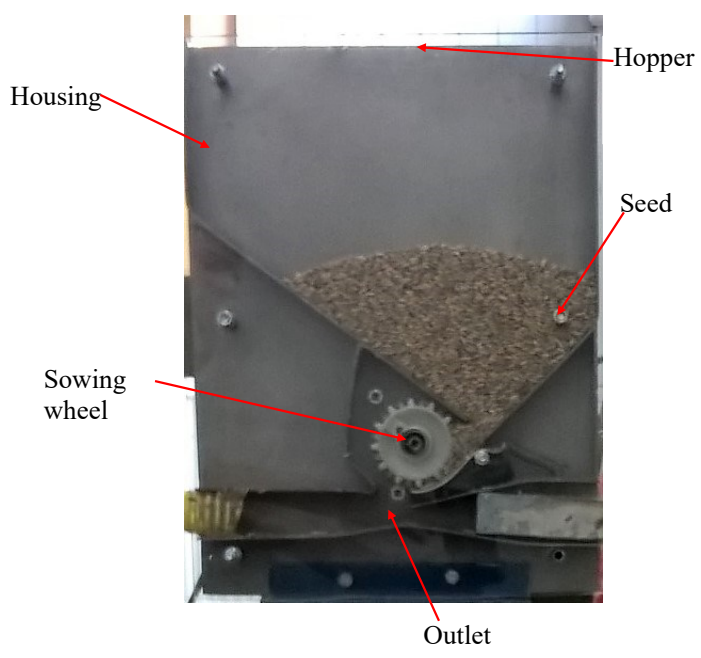

Fig. 10. View of the experimental test bench

\section{Conclusions}

The paper presents results from the conducted simulation tests of four different designs of peg sowing units. The numerical analyses conducted were intended to reflect the process of sowing wheat seeds. The discrete element method was used for the purpose of conducting the research. For all of the analysed geometries, identical boundary conditions were used in the form of mathematical models of contact, as well as physical and mechanical parameters of plant material.

The calculations performed made it possible to evaluate the discussed designs based on the obtained operational parameters. Analyses of the obtained results led to the conclusion that all four discussed cases have very similar performance parameters. The highest performance of $207.54 \mathrm{~g} / \mathrm{min}^{-1}$ was reached by the sowing unit with a trapezoidal peg profile.

None of the tested units were free from the negative phenomenon of uneven sowing. Initial observations showed that the lowest unevenness among the discussed designs could be found in the unit with a triangular profile of working elements.

Moreover, tests using an actual model of one of the tested seed sowing mechanism designs were performed. The aim of these tests was to check the correctness of the selected parameters (in particular the adoption of the Hertz-Mindlin contact model) for the numerical simulation of the seed stream feeding phenomenon. The obtained results in the form of time 
required to sow the same number of seeds as in the virtual simulations, confirmed the correctness of the virtual simulation performed.

The research leading to these results has received funding via the project $05 / 51 \mathrm{DSPB} / 3563$.

\section{References}

1. K. Lejman, Z. Owsiak, Analysis of seed tube construction in the aspect of longitudinal unevenness of sowing (Analiza konstrukcji przewodu nasiennego w aspekcie podtużnej nierównomierności wysiewu). Roczniki Nauk Rolniczych, 80, 143-149 (1994a)

2. K. Lejman, Z. Owsiak, Research of flexible rubber hoses seed (Badania elastycznych gumowych przewodów nasiennych). Roczniki Nauk Rolniczych 80, 135-141 (1994a)

3. J. Zarajczyk, J. Kowalczuk, Comparison of work quality for belt drill and cup-feed drill during onion seed sowing (Porównanie jakości pracy taśmowego i byżeczkowego zespołu wysiewającego przy siewie nasion cebuli). Inżynieria Rolnicza 5, 379-383 (2008)

4. P. A. Cundall, O. D. Strack, A discrete element model for granular assemblies. Geotehnique 29, 47-65 (1979)

5. P. Markowski, Influence of the sleted factors on loading a sowing unit of Regulice system with wheat seeds (Wplyw wybranych czynników na obciazienie nasionami przenicy zespolu wysiewającego systemu Regulice). Inżynieria Rolnicza, 3, 109-118 (2012)

6. P. Markowski, T. Rawa, Porównanie parametrów geometrycznych dwusegmentowych kołeczkowych zespołów wysiewających. Inżynieria Rolnicza, 10, 175-183 (2008)

7. A. A. Al-Mallahi, T. Kataoka, Application of fibre sensor in grain drill to estimate seed flow under field operational conditions. Computers and Electronics in Agriculture 121, 412-419 (2016)

8. T. Bagiński, P. Markowski, T. Rawa, Influence of selected factors on irregularity of spring barley seeds dosage using the press drill seeder. Technical Science, Pap. And Rep. 9, 5-11 (2006)

9. T. Rawa, P. Markowski, A. Lipiński, Determining attempt of influence of working parameters of pin sowing unit and the width between the rows and sowing speed on uniformity of dosage of wheat sedes (Próba określenia wptywu parametrów roboczych kołeczkowego zespolu wysiewającego oraz szerokości międzyrzędzi i prędkości siewu na równomierność dozowania nasion pszenicy). InżynieriaRolnicza, 6, 75-83 (2005)

10. H. Hertz, On the contact of elastic solids (Uber die berührung fester elastischerkörper). Miscellaneous Papers, Macmillan, 156 (1896)

11. R.D. Mindlin, H. Deresiewicz, Elastic spheres in contact under varying oblique forces. J. Appl. Mech. Trans. ASME 20, 327-344 (1953)

12. H. Kruggel-Emden, E. Simsek, S. Rickelt, S. Wirtz, V. Scherer, Review and extension of normal force models for the Discrete Element Method. Powder Technology 171, 157173 (2007)

13. C. Thornton, Z. Ning, A theoretical model for the stick/ bounce behaviour of adhesive, elasticeplastic spheres. Powder Technology 99, 154-162 (1998)

14. S. P. Timoshenko, J. N. Goodier, Theory of elasticity. New York: McGraw-Hill (1970)

15. G. Weir, S. Tallon, The coefficient of restitution for normal incident, low velocity particle impacts. Chemical Engineering Science, 60, 3637-3647 (2005) 
16. J. Łukaszuk, M. Molenda, J. Horabik, M. Montross, Variability of pressure drops in grain generated by kernel shape and bedding metod. Journal of Stored Products Research 45, 112-118 (2009)

17. J. M. Boac, R. P. K. Ambrose, M. E. Casada, R. G. Maghirang, D. E. Maier, Applications of discrete element method in modeling of grain postharvest operations. Food Engineering Reviews 6, 128 -149 (2014)

18. J. Horabik, M. Molenda, Parameters and contact models for DEM simulations of agricultural granular materials: A review. Biosystems Engineering 147, 206-225 (2016)

19. K. F. Malone, B. H. Xu, Determination of contact parameters for discrete element method simulations of granular systems. Particuology 6, 521-528 (2008)

20. B. K. Mishra, C. V. R. Murty, On the determination of contact parameters for realistic DEM simulations of ball mills. Powder Technology, 115, 290-297 (2001)

21. M. Moya, F. Ayuga, M. Guaita, P. Aguado, Mechanicalproperties of granular agricultural materials. Transactions of the American Society of Agricultural Engineers, 45, 1569-1577 (2002)

22. A. Ramirez-Gomez, M. Moya, F. Ayuga, Determination of the mechanical properties of powdered agricultural products and sugar. Particle\&Particle Systems Characterization 26, 220-230 (2009)

23. E. Tijskens, H. Ramon, J. De Baerdemaeker, Discrete element modeling for process simulation in agriculture. Journal of Sound and Vibration 266, 493-514 (2003)

24. J. Wiącek, M. Molenda, Moisture-dependent physical properties of rapeseed experimental and DEM modeling. International Agrophysics, 25, 59-65 (2011)

25. J. Wiącek, M. Molenda, J. Horabik, J. Y. Ooi, Influence ofgrain shape and intergranular friction on material behavior inuniaxial compression: experimental and DEM modeling. Powder Technology, 217, 435-442 (2012)

26. C. Gonzalez-Montellano, E. Gallego, A. Ramırez-Gomez, F. Ayuga, Three dimensional discrete element modelsfor simulating the filling and emptying of silos: analysis of numerical results. Computers\&Chemical Engineering 40, 22-32 (2012)

27. D. Markauskas, R. Kacianauskas, Investigation of rice grain flow by multi-sphere particle model with rollingresistance. Granular Matter, 13, 143-148 (2011)

28. J. M. Boac, M. E. Casada, R. G. Maghirang, J. P. Harner, Material and interaction properties of selected grains and oilseeds for modeling discrete particles. Transactions of the American Society of Agricultural \& Biological Engineers 53, 1201-1216 (2010)

29. F. Weigler, J. Mellmann, Investigation of grain mass flow in a mixed flow dryer. Particuology, 12, 33-39 (2014)

30. J. Horabik, Characterization of the physical properties of vegetable bulk materials important in storage processes (Charakterystyka właściwości fizycznych roślinnych materiałów sypkich istotnych w procesach składowania). Acta Agrophysica 54, 1-121 (2001)

31. M. Chutkowski, W. Zapała, Application of DEM method for the investigation of particle shape effect on a type of powder bed flow during silo discharge process (Zastosowanie metody DEM do badania wplywu ksztaltu ziaren na charakter wysypu materialu rozdrobnionego podczas opróżniania silosu). Inżynieria i Aparatura Chemiczna 54, 071-073 (2015) 